\title{
Potential feeding and spawning habitats of Atlantic bluefin tuna in the Mediterranean Sea
}

\author{
Jean-Noël Druon ${ }^{1, *}$, Jean-Marc Fromentin ${ }^{2}$, Florian Aulanier ${ }^{1,3}$, Jukka Heikkonen ${ }^{1,4}$ \\ ${ }^{1}$ Joint Research Centre of the European Commission, Maritime Affairs Unit, Institute for the Protection and \\ Security of the Citizen, Via Fermi, TP 051, 21027 Ispra (VA), Italy \\ ${ }^{2}$ IFREMER, Centre de Recherche Halieutique Méditerranéen et Tropical, Avenue Jean Monnet, BP 171, 34203 Sète, France \\ ${ }^{3}$ Present address: Gipsa-lab, 961 rue de la Houille Blanche, BP 46, 38402 Grenoble Cedex, France \\ ${ }^{4}$ Present address: Department of Information Technology, University of Turku, 20014 Turku, Finland
}

\begin{abstract}
Atlantic bluefin tuna Thunnus thynnus (ABFT) is a fish of high market value which has recently become strongly overexploited, notably in the Mediterranean Sea. This area is an essential habitat for ABFT reproduction and growth. We present here an approach for deriving the daily mapping of potential ABFT feeding and spawning habitats based on satellite-derived sea surface temperature (SST) and chl a concentration. The feeding habitat was mainly derived from the simultaneous occurrence of oceanic fronts of temperature and chl a content while the spawning habitat was mostly inferred from the heating of surface waters. Generally, higher chl a contents were found to be preferred for the feeding habitat and a minimum SST value was found for the spawning habitat. Both habitats were defined by the presence of relevant oceanographic features and are therefore potential and functionally-linked habitats. This approach provides, for the first time, a synoptic view of the potential ABFT habitats in the Mediterranean Sea. The model performs well in areas where both satellite data and ABFT observations are available, as $80 \%$ of presence data are in the vicinity of potential habitats. The computed monthly, seasonal and annual maps of potential feeding and spawning habitat of ABFT from 2003 to 2009 are in good agreement with current knowledge on ABFT. Overall, the habitat size of ABFT is about $6 \%$ of the Mediterranean Sea surface. The results displayed a strong seasonality in habitat size and locations as well as high year-to-year variations (30 to $60 \%$ ), particularly for the potential spawning habitat, which is key information for evaluating the utility of ABFT Marine Protected Areas in the Mediterranean Sea.
\end{abstract}

KEY WORDS: Habitat mapping - Bluefin tuna - Thunnus thynnus - Feeding · Spawning · Mediterranean Sea $\cdot$ Remote sensing $\cdot$ Satellite data

\section{INTRODUCTION}

Atlantic bluefin tuna Thunnus thynnus (ABFT) is a commercial fish species of high market value. The media has recently publicized the most prominent problems of many types of fisheries, notably ABFT, including severe overcapacity, open access in international waters, geographical expansion and deficient governance at both the international and national levels (Larkin 1996, García et al. 2005, Hilborn et al. 2005, Beddington et al. 2007). The scientific community, especially the scientific committee of the International Commission for the Conservation of Atlantic Tunas (ICCAT, the body mandated to monitor and manage ABFT resources), raised serious concerns over the West Atlantic ABFT stock status in the early 1980s, and over the Eastern ABFT stock status in the mid-1990s. A Total Allowable 
Catch (TAC) system, together with size limit regulations and time/area closures, were progressively implemented. These management regulations were ineffective in limiting catches in the Mediterranean Sea (mostly international waters) because of a lack of compliance and control (ICCAT 2007). Therefore, significant misreporting took place until 2007 and overexploitation carried on for more than $10 \mathrm{yr}$ (ICCAT 2009). These repetitive failures of ABFT management (as with those for many world fisheries) led to contemplation of alternative/complementary management options, such as the implementation of Marine Protected Areas (MPAs; Halpern \& Warner 2002, Sumaila et al. 2007).

However, improving management through the implementation of an adequate web of MPAs requires a reasonably accurate description of ABFT feeding and spawning habitats (de Juan \& Lleonart 2010). ABFT is a large pelagic fish which lives in the North Atlantic and adjacent seas, primarily the Mediterranean Sea (Mather et al. 1995, Fromentin \& Powers 2005). Among the Atlantic tunas, it has the widest geographical distribution and is the only one living permanently in temperate waters (Bard et al. 1998, Fromentin \& Restrepo 2001). The spatial distribution and movement of ABFT were suspected to be related to horizontal temperature gradients, as has been suggested for other tuna species (Laurs et al. 1984, Lehodey et al. 1997, Inagake et al. 2001). However, spatial dynamics of bluefin tuna species are likely to result from an interplay between biological processes and physical factors (both varying in time and space), such as preferred ambient temperatures, oceanographic structures (e.g. ocean fronts, upwelling areas), foraging and spawning events (Kitagawa et al. 2004, Royer et al. 2004, Schick et al. 2004, Block et al. 2005, Rooker et al. 2008, Lawson et al. 2010).

The accumulation of observations from electronic tagging has considerably improved our understanding of migratory patterns and preferential residency areas of ABFT in the North Atlantic (see e.g. Block et al. 2005, Sibert et al. 2006a, Walli et al. 2009), but not in the Mediterranean Sea because of the rather low level of successful electronic and conventional surveys (Fromentin 2010). This is problematic because the Mediterranean Sea is the primary spawning and fishing area of ABFT (Fromentin \& Powers 2005, ICCAT 2009). Therefore, we developed an alternative approach, assuming that specific oceanic structures derived from MODIS (MODerate resolution Imaging Spectroradiometer)-Aqua satellite sensors can be efficiently used to appraise ABFT-favourable habitats. To do so, we generalised the approach initi- ated by Royer et al. (2004), who assessed the role of the environment on ABFT spatial distribution in the northwestern Mediterranean to derive the potential ABFT feeding habitat in the whole Mediterranean Sea. More specifically, we tested whether the potential feeding habitat can be charted primarily from the detection of horizontal oceanic fronts of temperature and chl $a$. We further extended and tested the approach on the ABFT spawning habitat which is mainly inferred from the heating of surface waters. Specific ranges of chl a content were employed, as well as a minimum temperature value for the spawning habitat.

The originality of this work is thus that both habitats are solely based on relevant oceanographic structures that have been identified or hypothesised to play a key role on ABFT feeding and spawning activity. This oceanographic-driven approach allowed us to produce a daily mapping of ABFT potential habitats, but not of effective habitat which is always difficult to produce for marine animals (especially highly migratory ones). The daily maps of ABFT potential habitats were calibrated (tuned) with ABFT geo-located observations from scientific surveys or fisheries operations and then validated with an independent dataset of the calibration. Finally we computed monthly, seasonal and annual maps of potential feeding and spawning habitat of ABFT from 2003 to 2009 and interpreted our results with respect to general biological and ecological knowledge on ABFT. Thus, we quantitatively estimated, for the first time, the spatial and temporal variations of ABFT potential habitat, which is key information for evaluating the utility of ABFT MPAs in the Mediterranean Sea.

\section{DATA}

The objective of this work is to demonstrate the capacity of a model based on satellite-derived oceanic features to reveal the potential feeding and spawning habitat of ABFT in the Mediterranean Sea with high precision. To do so, 2 sources of data are needed: (1) narrow-band optical and thermal remote sensing data at large scale and medium resolution, and (2) geo-located ABFT occurrences.

\section{Satellite remote sensing data}

The habitat model uses the daily surface chl a content $(\mathrm{CHL})$ and sea surface temperature (SST) from 
the MODIS-Aqua sensor. This sensor was launched in July 2002 and is still active in 2011. The $4.6 \mathrm{~km}$ horizontal resolution of the NASA Standard Mapped Image is appropriate to enhance the meso-scale oceanographic features related to ABFT behaviour, as this species can cover up to $100 \mathrm{~km}$ daily. The night temperature (NSST) product was chosen in order to avoid the skin effect of daytime solar heating, and is therefore likely to provide a closer estimate of the mixed layer temperature. CHL and NSST daily data thus have a shifted timescale of $12 \mathrm{~h}$, NSST being sensed $12 \mathrm{~h}$ prior to CHL. The gain in NSST quality overrides the drift of oceanographic features that might occur in that delay. Indeed, the phase velocities of the Northern Current (the major component of the circulation in the western Mediterranean Sea) are generally equal to or lower than $10 \mathrm{~km} \mathrm{~d}^{-1}$, i.e. one satellite pixel per $12 \mathrm{~h}$ period (Sammari et al. 1995). This approach is consistent with the observation of well-identified CHL fronts between 2 consecutive days.

In order to highlight frontal structures for the feeding habitat, we must calculate the horizontal gradient that tends to erode the habitat coverage around missing values. To reduce the occurrence of irregular SST or CHL fields due to cloud occlusion, several iterations of median filtering were applied to the original data when sufficient information was available in the neighbourhood of 2 pixels, i.e. $9.2 \mathrm{~km}$. At the last iteration, the filtered values were superimposed with the original data to avoid divergence from the original information. A Gaussian filter was then applied to decrease the error in recovered pixel value, which is likely to be significant in areas of strong gradient. The quality of the recovered data in the vicinity of missing values was tested on SST and CHL data. To do so, daily data with good coverage was impaired with a cloud mask from another day. The mean absolute error for SST between the recovered and original values was about $0.2^{\circ} \mathrm{C}$ (Aulanier \& Druon 2010) which remains below the general mean error of satellite sensors $\left(\sim 0.5^{\circ} \mathrm{C}\right)$. The corresponding mean error for CHL recovery is $0.005 \mathrm{mg} \mathrm{m}^{-3}$. Considering the range of $\mathrm{CHL}$ where ABFT was observed (5th to 95th percentile range $=0.07$ to $0.33 \mathrm{mg} \mathrm{m}^{-3}$ ), this would lead to errors of about 7 and $1.5 \%$, respectively. This is also significantly below the mean error of the satellite-derived CHL estimates in oceanic waters deeper than $200 \mathrm{~m}, 33 \%$ for MODIS-Aqua (S. Bailey pers. comm.). The median filter and Gaussian smoothing procedure allows an increase in the SST and CHL coverage of $\sim 8 \%$. The relative gain in coverage is much higher after the gradient calculation, with $42 \%$ for SST and $38 \%$ for CHL. As the feeding habitat requires the horizontal gradient computation, the relative increase of coverage due to median filtering is high, i.e. about $57 \%$. Since the spawning habitat uses only the original SST and CHL data, the increase of coverage is similar to the original data recovery (about $8 \%$ ). The use of the median filter and Gaussian smoothing is therefore particularly relevant in the case of dappled cloud occlusions for the potential feeding habitat.

If the same-day SST and CHL data are used for computing the horizontal gradient of SST and CHL (feeding habitat) and the temporal gradient of SST (spawning habitat, see 'Habitat model methodology' and Fig. 2), a 3-day composite of SST and CHL data is created to be used as a preferred range of values for the spawning habitat. As these environmental variables generally show a low variability within $24 \mathrm{~h}$, data from the previous and the following days are integrated in order to gain coverage. Current-day data are superimposed on the 3-day average to retain the closest measurement for the computation of the daily spawning habitat (see Fig. 2). Neither the horizontal nor the temporal gradient are computed with these 3-day composites.

\section{Atlantic Bluefin tuna observations}

The ABFT geographical positions came from 3 sources of information: (1) aerial surveys, (2) tagging surveys and (3) fishing operations. Aerial surveys have been carried out by Ifremer since 2000 in the northwestern Mediterranean Sea to compute an index of relative abundance from fishery-independent observations (Fromentin et al. 2003, Bonhommeau et al. 2010). During these surveys, the exact position of each detected ABFT school (mostly juveniles feeding on small pelagic fish) is recorded using a global positioning system (GPS). The second source of information was 2 Ifremer tagging programs (both electronic and conventional) carried out in the northwestern Mediterranean Sea (Fromentin 2010). This dataset included the GPS positions of the released ABFT (i.e. locations at tagging) for which individual length or weight information was also available. Note that only the geographical positions of the tagging releases were employed, without considering the positions reconstructed from the archived data which display low spatial precision. Thirdly, we collected ABFT geographical positions from commercial fisheries, using extensive logbook information provided by a French purse seiner. This database 
included 1258 sightings with precise geographical positions (i.e. having an error lower than 1 ' of latitude/longitude; Fig. 1). These data correspond to GPS positions of ABFT schools that were caught in the Western and Central Mediterranean Sea from March to October between 2002 and 2010. The approximate fish weight (mean value of schools estimated by fishermen) was available for 727 observations showing that $40 \%$ of ABFT accounted for in our data were adult fish $(>30 \mathrm{~kg})$. While most scientific surveys (aerial survey and tagging) took place in known feeding areas (e.g. the Gulf of Lions), a large fraction of the purse seine-derived data is in the vicinity of the targeted spawning grounds, so that the ABFT observations cover both the feeding and the spawning behaviors. The entire ABFT dataset was finally separated into 2 approximately equal sized sets, one employed for model calibration and the other for model validation.

\section{HABITAT MODELLING METHODS}

Our approach is based on a technique used in other research studies for mapping marine habitat which 'recognised correlation between environmental parameters and ecological character, such that mapping environmental parameters in an integrated manner can successfully be used to produce ecologi-

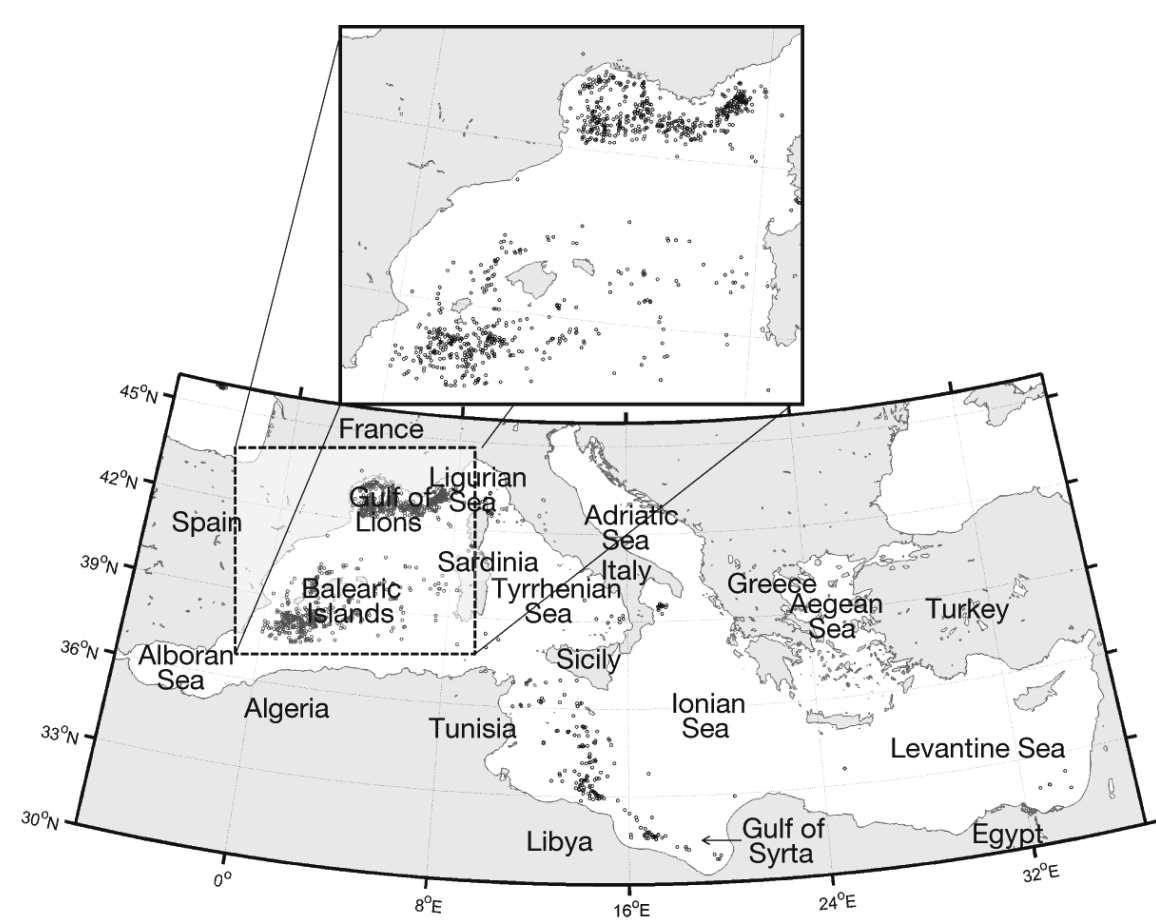

Fig. 1. Thunnus thynnus. Geo-located presence data for Atlantic bluefin tuna $\left({ }^{\circ}\right)$ in the Mediterranean Sea cally relevant maps' (Connor et al. 2006). This approach is commonly referred to as multi-criteria evaluation projected in a geographical grid (i.e. NASA-MODIS regular grid using the equidistant cylindrical projection). The main gridded data to be used were (1) CHL (1-day data and 3-day composite), (2) NSST (1-day data and 3-day composite), (3) the horizontal gradient of daily NSST and CHL, and (4) the mean temporal gradient of NSST over $5 \mathrm{~d}$ and over several weeks (Fig. 2). The originality of the model lies in the fact that the habitat is largely defined by the vicinity of ABFT to specific oceanic features which are believed to be relevant to a given behaviour, i.e. CHL and SST fronts for feeding or monthly heating of surface waters for spawning. A specific CHL range (and a minimum SST for the spawning habitat) at the position of the identified oceanic features are also used to detect the preferred habitat. Thus we derived a potential habitat identifying the favourable environmental conditions in the vicinity (few $\mathrm{km}$ ) of ABFT observations. This is different to the effective habitat that defines the positions and/or the conditions at the locations of the sightings. The following sections describe more technically how and why the criteria were chosen for each habitat and how the ABFT observations were used to optimize the model parameterization.

\section{ABFT feeding habitat}

ABFT is a visual predator that is often distributed at the vicinity of thermal and chlorophyll fronts, so these oceanographic structures appear to play a key role in its feeding, growth and physiology (e.g. Humston et al. 2000, Royer et al. 2004, Teo et al. 2007, Schick \& Lutcavage 2009). Many zooplankton species are abundant in fronts (Le Fèvre 1986), and the concentration of small and large zooplankton in convergence areas attracts higher trophic level predators leading to the assemblage of a complete pelagic food web (Olson et al. 1994, Munk et al. 1995). Although Brill et al. (2002) and Schick et al. (2004) found no correlation between juvenile ABFT presence and SST fronts, they did not specifically analyse CHL fronts. Moreover, Brill et al. (2002) showed that ABFT tend to remain in the frontal area 


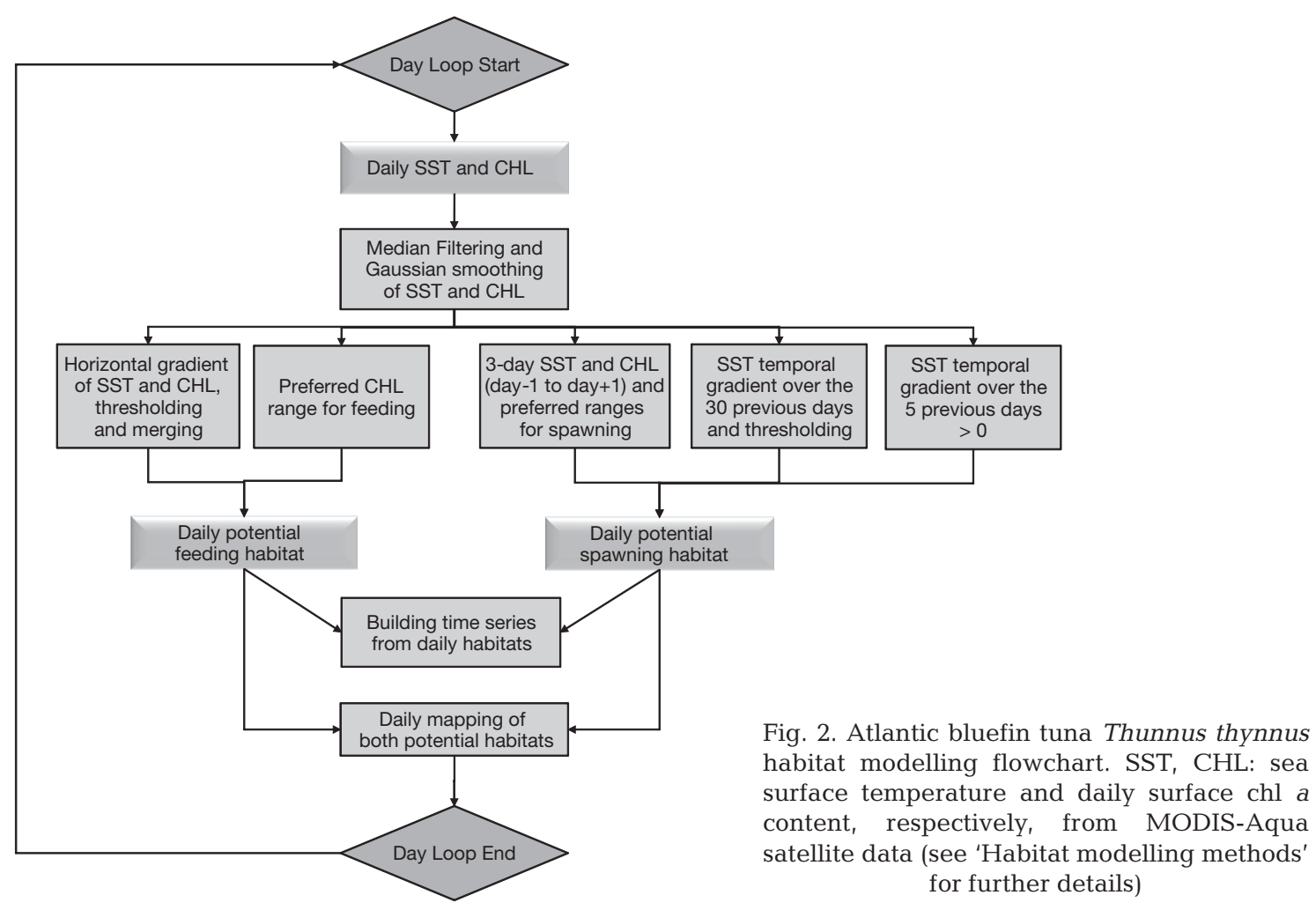

between the turbid and phytoplankton-rich plume and the clear oligotrophic water (using a satellitederived diffuse attenuation coefficient). This has been confirmed by more recent works which showed that ABFT seems to prefer rather low to medium chl a concentrations in the Mediterranean Sea, i.e. below $\sim 0.50 \mathrm{mg} \mathrm{m}^{-3}$ (Royer et al. 2004, Druon 2010). Our analysis on 3-day CHL composites indicated similar values with $90 \%$ of ABFT sightings in the range from 0.07 to $0.33 \mathrm{mg} \mathrm{m}^{-3}$ (data not shown). Past archival tagging experiments and fisheries data showed that ABFT can sustain a large range of water temperature, i.e. from 3 to $29^{\circ} \mathrm{C}$ (Fromentin \& Powers 2005). In our study, ABFT was observed in the range between 10 and $27^{\circ} \mathrm{C}$ (3-day SST composite, $\mathrm{n}_{\text {total }}=$ 1170) with no difference in temperature preference between juveniles and adults. Therefore, ABFT feeding habitat was defined by the 3 following variables: SST fronts, CHL fronts and CHL.

The front enhancement is calculated with an edgedetection algorithm using CHL and SST daily data. Ullman \& Cornillon (2000) showed that automated edge-detection algorithms perform better than the histogram methods in detecting fronts given clear viewing conditions. Spurious detections resulting from cloud masking were avoided by detecting the overlap of SST and CHL fronts. Since SST and CHL are affected differently by clouds due to spectral dif- ferences (near-infrared versus visible), the detection of overlapping fronts is likely to result from oceanic processes and not due to atmospheric effects. In other words, the co-identification of SST and CHL fronts is used in the model to prevent respective cloud edge issues. This edge-detection method based on the computation of horizontal gradient was successfully applied to demonstrate the presence of ABFT schools at the vicinity of CHL and SST fronts (Royer et al. 2004). In the present study, a 2 stage procedure was applied: (1) SST and CHL images were processed using median and Gaussian filters (see 'Data') prior to computing the norm of the horizontal gradients, and (2) a specific minimum threshold estimated using ABFT geo-located data during the calibration process was then applied to remove secondary features and highlight relevant fronts. Note that the ABFT observations were used solely for the second step and not in the edge-detection algorithm itself. The overlap of the relevant daily CHL and SST fronts was the main criterion for representing the potential feeding habitat. Note however that the $\mathrm{CHL}$ front is retained here as a major criterion for the feeding habitat, the SST front being mainly used as a cloud-edge masking. Therefore, the potential feeding habitat (Fig. 2) resulted from (1) the overlap of CHL and SST frontal areas and (2) a low CHL (range also estimated by the calibration). 


\section{ABFT spawning habitat}

Environmental conditions suitable to spawning of ABFT (and large pelagic fish in general) have been studied for decades. ABFT spawning takes place in warming waters of the Mediterranean Sea from midMay to early July and of the Gulf of Mexico around May (see Nishikawa et al. 1985, Mather et al. 1995, Schaefer 2001). These studies, which were mostly based on larvae surveys and fisheries data, were recently confirmed by electronic tagging information (e.g. Teo et al. 2007), which further gave details about ABFT movement patterns, diving behavior, and thermal biology during the spawning period. Spawners aggregate in large shoals in areas that should have, on average, good potential for larval survival and development: primarily, well-stratified surface waters and a significant abundance of small zooplankton, mainly copepods and copepoda nauplii, on which larvae of bluefin tuna species feed (Uotani et al. 1990, Fromentin \& Powers 2005). Zooplankton population, when settled, may control the primary production after the spring bloom and can hold down the chlorophyll content to low values $(\sim 0.05$ to $0.15 \mathrm{mg} \mathrm{m}^{-3}$ ). Since surface temperature integrates the degree of mixing with subsurface waters, low turbulence levels in surface waters are traced by a high SST increase in springtime. High-frequency mixing episodes (e.g. wind events) that reveal temporary poor weather conditions and are identified as unfavourable spawning conditions are spotted by a SST decrease for several consecutive days (Fig. 2). Information from larval surveys in the Mediterranean Sea (Nishikawa et al. 1985, García et al. 2003, 2005) and observation from spawning in captivity (Lioka et al. 2000) indicate that spawning in the Mediterranean Sea always occurs in warm waters $\left(>20^{\circ} \mathrm{C}\right)$ and most often in waters ranging from 22.5 to $25.5^{\circ} \mathrm{C}$ (Schaefer 2001, Rooker et al. 2007). From these elements, the criteria that were retained for the spawning habitat (Fig. 2) are (1) a high increase of SST over several weeks, (2) an increase of SST over the previous $5 \mathrm{~d}$, (3) a minimum SST value (3-day composite) and (4) a relatively low CHL (3-day composite).

\section{Calibration of the habitat model}

The criteria that were retained for both potential habitats imply the estimation (calibration) of 11 parameters, of which 5 are for the feeding habitat and 6 for the spawning habitat. The potential feeding habitat was defined using a minimum horizontal gradient of $\operatorname{SST}\left(\nabla_{\mathrm{h}} \mathrm{SST},{ }^{\circ} \mathrm{C} \mathrm{km}^{-1}\right)$ and of $\mathrm{CHL}\left(\nabla_{\mathrm{h}} \mathrm{CHL}, \mathrm{mg} \mathrm{m}^{-3}\right.$ $\mathrm{km}^{-1}$ ), together with a preferred CHL range (mg $\mathrm{m}^{-3}$ ). The width of the edge detector window (in number of pixels) also determines the size of oceanic structures which are relevant for ABFT feeding. The potential spawning habitat was primarily determined by the mean temporal gradient of SST $\left({ }^{\circ} \mathrm{C} \mathrm{d}^{-1}\right)$ over a given number of days (i.e. $30 \mathrm{~d}$, see 'Results: Main characterisitics of the habitat'), considering that a minimum number of SST differences (\%) is required to obtain consistent mean SST gradients with time. The unfavourable high-frequency mixing phenomena for spawning such as wind events were traced by a positive mean of SST difference over a period of $5 \mathrm{~d}$ prior to the day of habitat computation (Fig. 2). Finally, a minimum SST value and a specific range of $\mathrm{CHL}\left(\mathrm{mg} \mathrm{m}^{-3}\right)$ also contributed to the identification of the spawning habitat.

The calibration of the model (i.e. estimation of the parameters that may be seen as a model tuning) was performed using a fraction of our ABFT geo-located data with no a priori knowledge as to which habitat each observation belonged. Therefore each observation has the same weight in the calibration process and can be classified closer to either habitat depending on its position and the parameterization of both habitats. In other words, the model calibration determines the feeding and spawning habitat boundaries by taking into account all the ABFT observations and the selected environmental criteria. To do so, we defined the minimization function $\left(f_{\min }\right)$ as follows:

$$
f_{\min }=\sum D_{\text {out }}-W_{f} \sum D_{\text {in }}
$$

where, for a given parameterization, $D_{\text {out }}$ are the distances between ABFT observations and the closest habitat boundary when the fish are outside of the potential habitat. $D_{\text {in }}$ are the same distances when the fish are inside the habitat (Fig. 3) and $W_{f}$ is a weighting coefficient. Since the potential habitat is defined by specific oceanic features (and not directly by ABFT observations), the habitat size is variable and could be chosen to be large enough to enclose most or all ABFT sightings. However, we examined whether a reduced habitat size could in addition restrict the distances from presence data to the closest habitat. To do so, we introduced the factor $W_{f}$. Depending on the value of $W_{f}$, and the calibrated parameterization, a single observation may be located inside or outside the potential habitat (e.g. $D_{\text {in } 4}$ and $D_{\text {out4 }}$ in Fig. 3). In other words, $W_{f}$ has been introduced to explore whether an optimum compromise exists between the size of the habitat and the dis- 

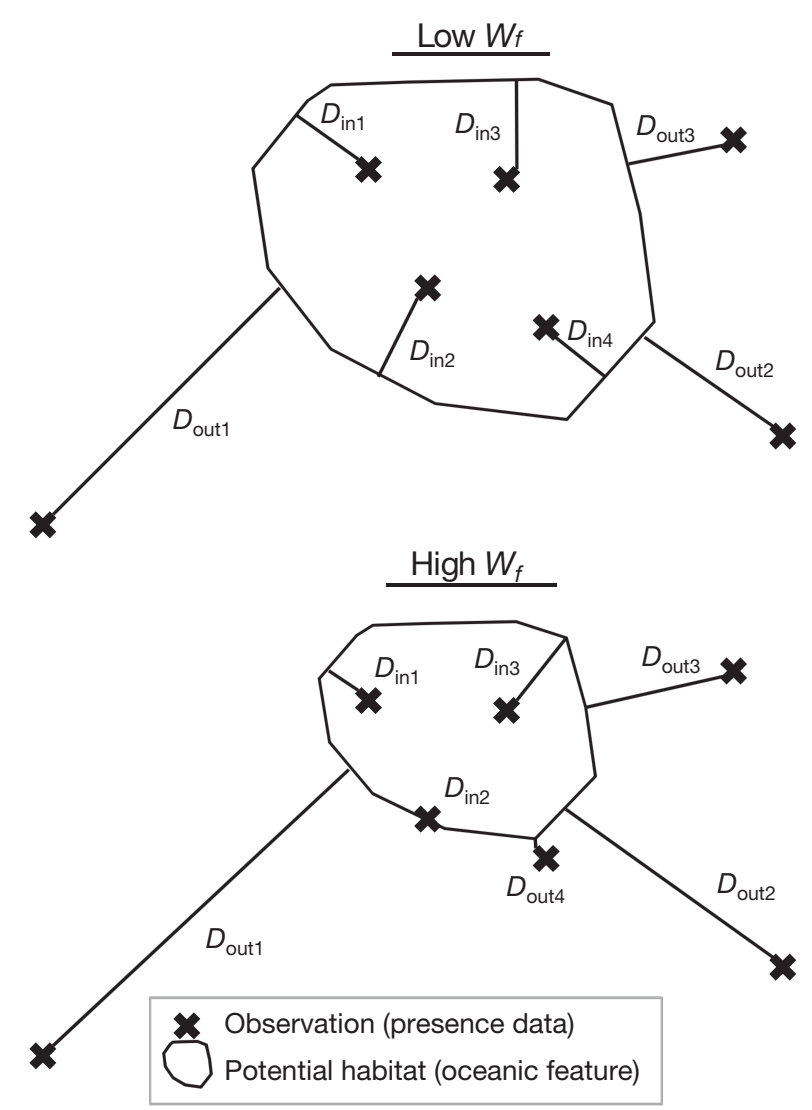

Fig. 3. Thunnus thynnus. Relative influence of the weight factor value $W_{f}$ on habitat size and distances from Atlantic bluefin tuna presence data to the closest potential habitat: (A) low $W_{f}$, (B) high $W_{f}$. Note that an observation may exit the potential habitat when $W_{f}$ increases. For bluefin tuna in our model, optimal $W_{f}=3.1$ (see 'Calibration of the habitat model' for details)

tances from observations to these habitats: the higher the value of $W_{f}$, the lower the size of the habitat, thus the higher the number of ABFT observations outside of the habitats. Conversely, a habitat that included all of the geo-located ABFT observations would cover a great part, or the whole of the Mediterranean Sea, which would be of little utility.

It is expected that a proportion of ABFT observations are outside of the habitats because fish may seek favourable habitat and/or migrate towards or away from a habitat, especially during spawning migration. In addition, clouds may mask potential habitats in the vicinity of ABFT observations. To circumvent these 2 difficulties, the 90th percentile of the distances is used to optimize the parameter set (i.e. $10 \%$ of the highest distances are removed so as to minimize $f_{\min }$ ). Note that above the 90th percentile, the increase of the percentile distances between the observations and closest habitat is about twice that of the distance below the 90th percentile, whatever the value of $W_{f}$.

With the purpose of seeking an optimal value of $W_{f}$ for ABFT (i.e. an optimal habitat size), we calibrated the model using the minimization function for a wide range of $W_{f}$ values (from 1 to 7 , with a step of 0.1 around the optimum value). A value for $W_{f}$ of 3.1 was found to optimize the compromise between habitat size and number of ABFT observations outside of habitat. This optimization leads to a potential habitat which is, on average, less than half the size of that found with a value $W_{f}$ of 1 .

The model calibration based on the minimization function $f_{\min }$ was performed using the 'fminsearch' function of Matlab software (Matlab 2006). The function is made for unconstrained nonlinear optimization of a scalar objective function of several variables and is based on the Nelder-Mead simplex (direct search) method (Nelder \& Mead 1965). In our case, the 11 parameters to be optimized and their initial estimates (mainly from the literature) were determined by educated guesses from the previous research. We noticed that after 80 to 120 iterations the solution converged without any large changes in parameter and objective function values, thus providing an accurate calibration solution.

Finally, the estimation of the model parameters was performed using a fraction of the ABFT geo-located observations (650 sightings). In order to validate the model, we additionally ran the calibrated model with the other fraction of ABFT observations (including 618 sightings).

\section{RESULTS}

\section{Performance of the model}

Of the 650 observations used for the calibration, 210 occurred at a place and time during which suitable satellite data for the MODIS-Aqua sensor could be obtained (i.e. no cloud coverage). Of these $210 \mathrm{ob}-$ servations, 100 and 110 were related to the feeding and spawning habitat, respectively: $31 \%$ and $40 \%$ were located within the potential feeding or spawning habitats, respectively, and $80 \%$ of the observations were within $11.2 \mathrm{~km}$ and $10.6 \mathrm{~km}$ of the feeding and spawning habitats, respectively (Table 1). In other words, $80 \%$ of the observations were less than 3 pixels distant from the potential habitat (pixels are of $4.6 \mathrm{~km}$ resolution). The histograms of the distances from ABFT observations to the closest habitat boundary (positive values) displayed a negative exponen- 
Table 1. Number of ABFT presence data and 50th (i.e. median) and 80th percentile distances to the closest habitat for the calibration and validation of the habitat model (see 'Habitat modelling methods' and Figs. 2 \& 3)

\begin{tabular}{|lccc|}
\hline Modelling step & $\mathrm{n}$ & \multicolumn{2}{c|}{$\begin{array}{c}\text { Percentile distance }(\mathrm{km}) \\
\text { 50th }\end{array}$} \\
& \multicolumn{3}{c}{ 80th } \\
\hline Feeding habitat & & & \\
Calibration & 100 & 3.0 & 11.2 \\
Validation & 171 & 0 & 7.3 \\
Spawning habitat & & & \\
Calibration & 110 & 0.7 & 10.6 \\
Validation & 49 & 0 & 6.1 \\
\hline
\end{tabular}

tial form, as would be expected of a diffusive process from the favourable habitats (Fig. 4A).

Among the 618 observations used for the validation, 220 presented suitable satellite coverage (171 and 49 for the feeding and spawning habitats respectively). The distances from the closest habitat boundary were also regularly distributed (Fig. 4B). Regarding the feeding habitat, $53 \%$ of the observations were within the habitat, while $80 \%$ of the observations were within $7.3 \mathrm{~km}$. These statistics are thus better than those for the calibration which gives good support to the feeding habitat model and its estimated parameters. For the spawning habitat, the number of observations ( $\mathrm{n}=49$ ) was unfortunately lower and probably too low to reach any firm indications about the validation. However, the general pattern of the histogram is also regular and the results were significantly better than for the calibration (the 80th percentile distance is $6.1 \mathrm{~km}$, see Table 1). Among the 8 outliers (i.e. above $50 \mathrm{~km}$ ) for both the calibration and validation (Fig. 4), 5 were either due to a low habitat coverage or, for the spawning habitat, to a relatively low number of SST differences in the 30 -day period. In the 3 other cases, it is likely that the tuna schools were migrating or being disturbed while chased by fishermen.

To further test that the potential habitat is not randomly distributed and actually represents ABFT spatial distribution, we calculated the distances separating the calibrated habitat with an equivalent number of observations (i.e. 528) being randomly distributed in the Mediterranean Sea throughout the year. Compared to the calibration results, the 80th percentile distances were $30 \times$ higher for the spawning habitat (i.e. $181 \mathrm{~km}$ ) and $16 \times$ higher for the feeding habitat (i.e. $135 \mathrm{~km}$ ). This result shows that the potential habitat fitted from ABFT geo-located observations is significantly different from the one that could be
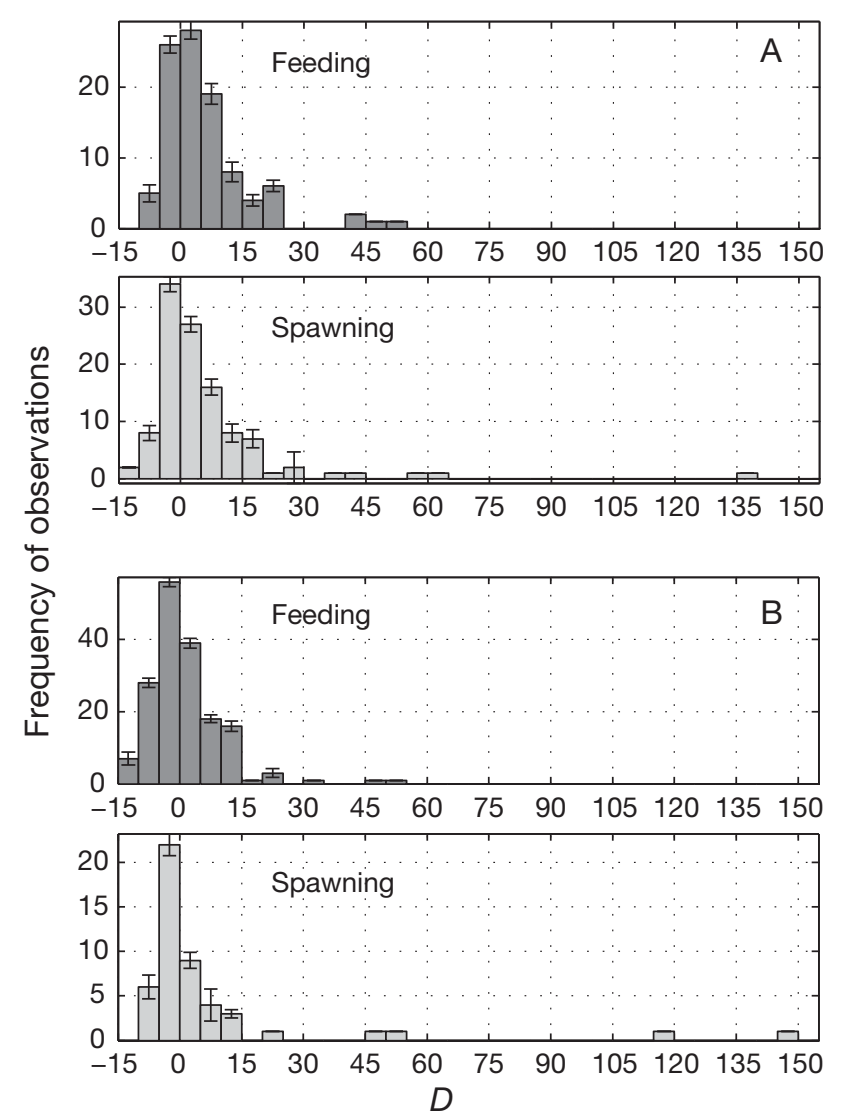

Fig. 4. Distances $(D)$ separating the presence data for Atlantic bluefin tuna from the closest predicted habitat boundary for (A) model calibration and (B) model validation. Note that positive values correspond to observations outside the habitat $\left(D_{\text {out }}\right)$ and negative values to observations within the habitat $\left(D_{\text {in }}\right)$ (see 'Calibration of the habitat model' and Fig. 3)

obtained with random data. In other words, the potential habitat of ABFT in the Mediterranean Sea is not randomly distributed in space and time.

\section{Main characteristics of potential habitat}

The values for the minimum horizontal gradient of SST and CHL that characterizes fronts relevant for the potential feeding habitat of ABFT in the Mediterranean Sea were found to be $0.11^{\circ} \mathrm{C} \mathrm{km}^{-1}$ and $0.0053 \mathrm{mg} \mathrm{m}^{-3} \mathrm{~km}^{-1}$ respectively. The optimal range of CHL obtained for the ABFT feeding habitat is between 0.11 and $0.34 \mathrm{mg} \mathrm{m}^{-3}$, which is consistent with Royer et al. (2004), who studied ABFT feeding habitat in the northwestern Mediterranean and with Polovina et al. (2001), who performed a large-scale study of forage habitats over the North Pacific. The potential spawning habitat of ABFT in the Mediter- 
ranean Sea is mainly defined by a mean SST difference during a floating period of $30 \mathrm{~d}$ (dtSST) above $0.35^{\circ} \mathrm{C} \mathrm{d}^{-1}$, which corresponds to the formation of a stable thermocline in spring. Different integration times were tested from 20 to $45 \mathrm{~d}$, but $30 \mathrm{~d}$ provided the best model performances, possibly because this period corresponds approximately to the thermocline build-up in spring. The minimum number of SST differences to ensure that the calculated dtSST is relevant was found to be $9 \mathrm{~d}$ over the $30 \mathrm{~d}$ period ( $34 \%$ ). Taking the wind-induced decrease of SST during the $30 \mathrm{~d}$ period into account, the overall SST increase was generally about $5^{\circ} \mathrm{C}$. A minimum SST of $19^{\circ} \mathrm{C}$ was also found to characterize the spawning habitat, which is significantly lower than the values assumed in the literature (about $24^{\circ} \mathrm{C}$ ). However, the comparison of in situ and satellite-derived measurement of SST is difficult, mainly due to the different water depths sensed by the 2 techniques (a few meters vs. a few micrometers respectively). The range of CHL found ( 0.08 to $0.15 \mathrm{mg} \mathrm{m}^{-3}$ ) is globally lower than for the forage habitat which is in agreement with general knowledge and further generates a low overlap with the feeding habitat.

It is worth noting that $80 \%$ of $\mathrm{ABFT}$ observations $>40 \mathrm{~kg}$ were observed in a CHL range from 0.06 and $0.15 \mathrm{mg} \mathrm{m}^{-3}$, while $80 \%$ of ABFT observations $<40 \mathrm{~kg}$ were observed in a CHL range from 0.10 and $0.30 \mathrm{mg} \mathrm{m}^{-3}$ (3-day CHL composite). This result suggests that most adult ABFT in our data have a preference for CHL content potentially favourable for spawning, and that most juvenile ABFT have a preference for CHL content potentially favourable for feeding. Of ABFT data closest to the potential feeding habitat, $90 \%$ were juvenile fish $\left(<30 \mathrm{~kg}, \mathrm{n}_{\text {total }}=\right.$ 178). Consequently, we can assert that the potential feeding habitat in this study is mainly focused on juvenile ABFT. Of ABFT observations closest to the potential spawning habitat, $83 \%$ weighed $>20 \mathrm{~kg}$ (limit for which maturity starts in the Mediterranean Sea, i.e. at age $4, \mathrm{n}_{\text {total }}=71$ ). The 12 ABFT observations $<20 \mathrm{~kg}$ (remaining $17 \%$ ) were located in the Balearic Islands area in June where both habitats are particularly close to each other. Note that if we focus on the validation exercise only, $97 \%$ of the ABFT closest to the spawning habitat were adults $(>30 \mathrm{~kg}$, $\mathrm{n}_{\text {total }}=33$ ) and the mean weight was $85 \mathrm{~kg}$.

\section{Main spatial patterns}

The potential feeding habitat of ABFT was recurrent ( $>15 \%$ of the time) in several specific and well defined areas, such as the Alboran Sea, the Gulf of Lions, the Ligurian Sea, the southern Adriatic Sea and the northern Aegean Sea (Fig. 5A). In contrast, the Tyrrhenian Sea and most of the central and southern part of the eastern Mediterranean Sea showed a low occurrence of potential forage habitat $(<5 \%$ of the time). Whereas the feeding habitat was concentrated on the edge of the basin, the main potential spawning grounds $(>1.6 \%$ of the time, Fig. 6A) were mostly in the central parts of the western Mediterranean Sea (around the Balearic Islands and Sardinia as well as north of the Algerian and Sicilian coasts) and in the Gulf of Syrta, east of Sicily, the central Aegean Sea and the northern Levantine Sea. Note that there is little overlap between both habitats. While the feeding habitat was rather continuous and stretched out, the spawning habitat was patchier with a round shape. This is understandable as the feeding grounds are mostly influenced by the general circulation, while the spawning habitat is primarily affected by the spring surface heating, which displays a higher year-to-year spatial variability. From the daily to seasonal time scales (see anomaly maps, Fig. 6B-H), the integration of SST differences over $30 \mathrm{~d}$ emphasizes mostly large and continuous patches of potential spawning habitat.

\section{Spatial variability at the annual scale}

The computation of annual anomalies of habitat occurrence compared to the mean value for the period 2003-2009 showed that the main spatial patterns significantly changed year-to-year (Figs. 4 \& 5). For instance, the heatwave during the summer of 2003 in Europe is likely to have caused a strong reduction in the feeding habitat of the northwestern Mediterranean (except in the Gulf of Lions), while it increased in the southwestern Mediterranean Sea (from \pm 5 to $\pm 15 \%$; Fig. $5 \mathrm{~B}$ ). A positive anomaly in the northwestern Mediterranean Sea was detected in 2005-2008. Even if patterns varied locally, the anomaly of the feeding habitat from 2003 to 2005 was globally low or negative at the scale of the central and eastern Mediterranean Sea, while it was positive for the period 2006-2009. The ABFT feeding habitat also shows a strong inter-annual variability in the Adriatic Sea in 2003 and 2009 with strong anomalies (from 10 to $30 \%$ ) between the northeast Adriatic coastal area and the central and eastern basin (Fig. 5B,H). Similar differences between 2003 and 2009 also took place in the Sicilian Strait, the northern Ionian Sea and western Aegean Sea. The spawning habitat displayed 

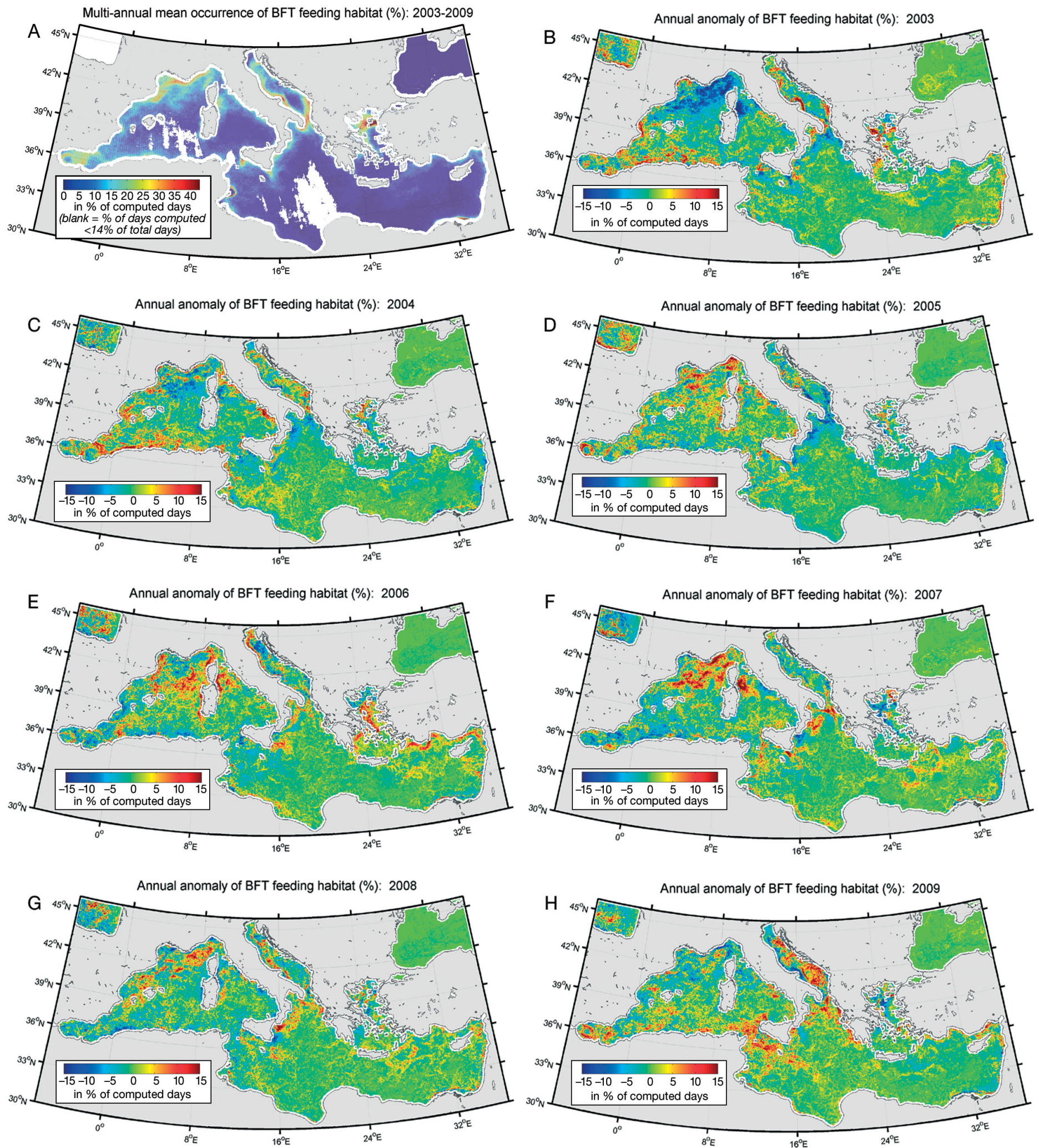

Fig. 5. Thunnus thynnus. (A) Multi-annual (2003-2009) composite of the estimated Atlantic bluefin tuna feeding habitat in the Mediterranean Sea and (B to H) annual anomaly maps (2003 to 2009) expressed in percentage of total days where satellite data was available. Note that a minimum coverage frequency of $14 \%$ was applied on (A) to show a consistent map 

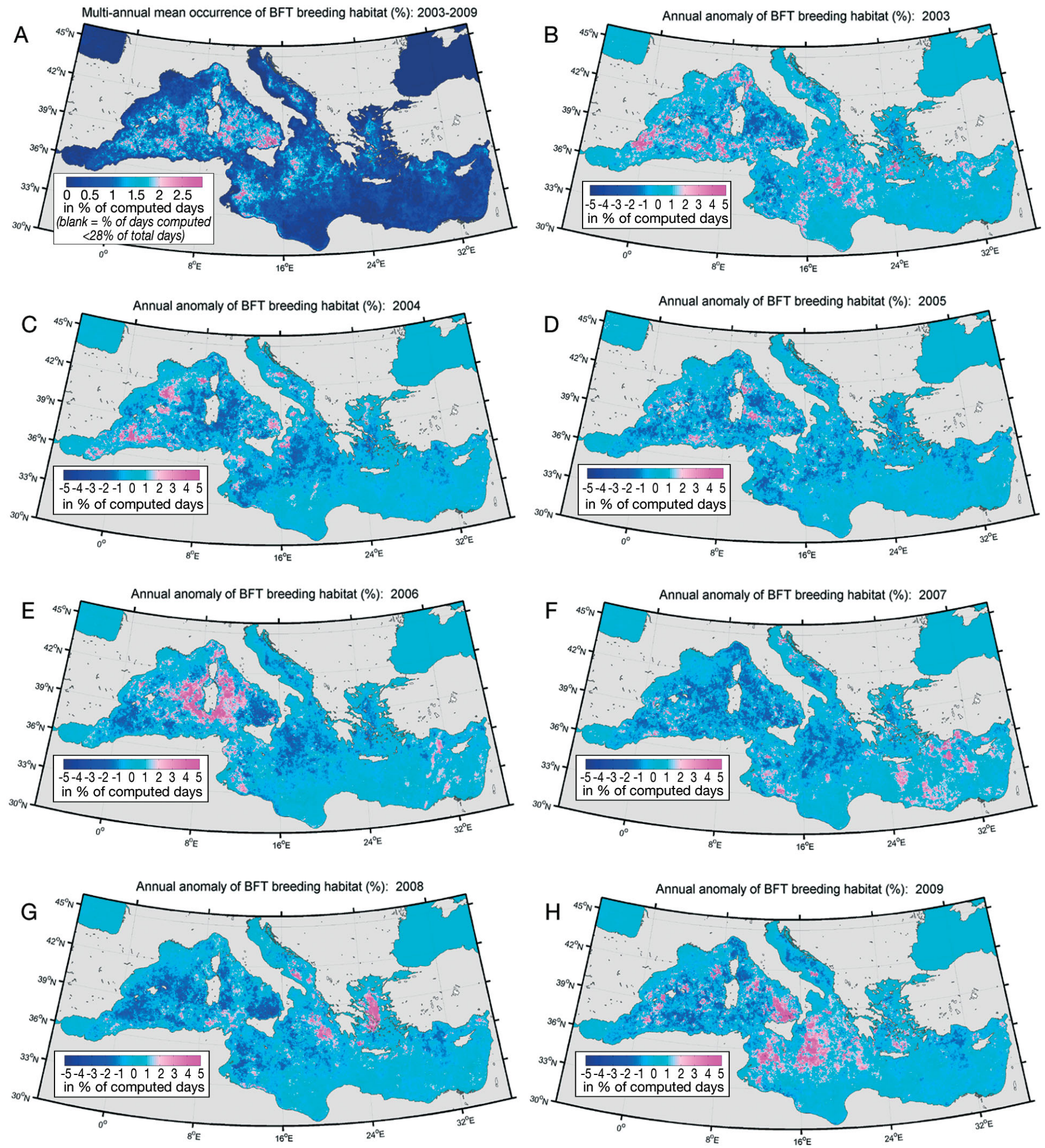

Fig. 6. Thunnus thynnus. (A) Multi-annual (2003-2009) composite of the predicted Atlantic bluefin tuna spawning habitat in the Mediterranean Sea and (B to H) annual anomaly maps (2003 to 2009) expressed in percentage of total days where satellite data was available. Note that a minimum coverage frequency of $28 \%$ was applied on (A) to show a consistent map 

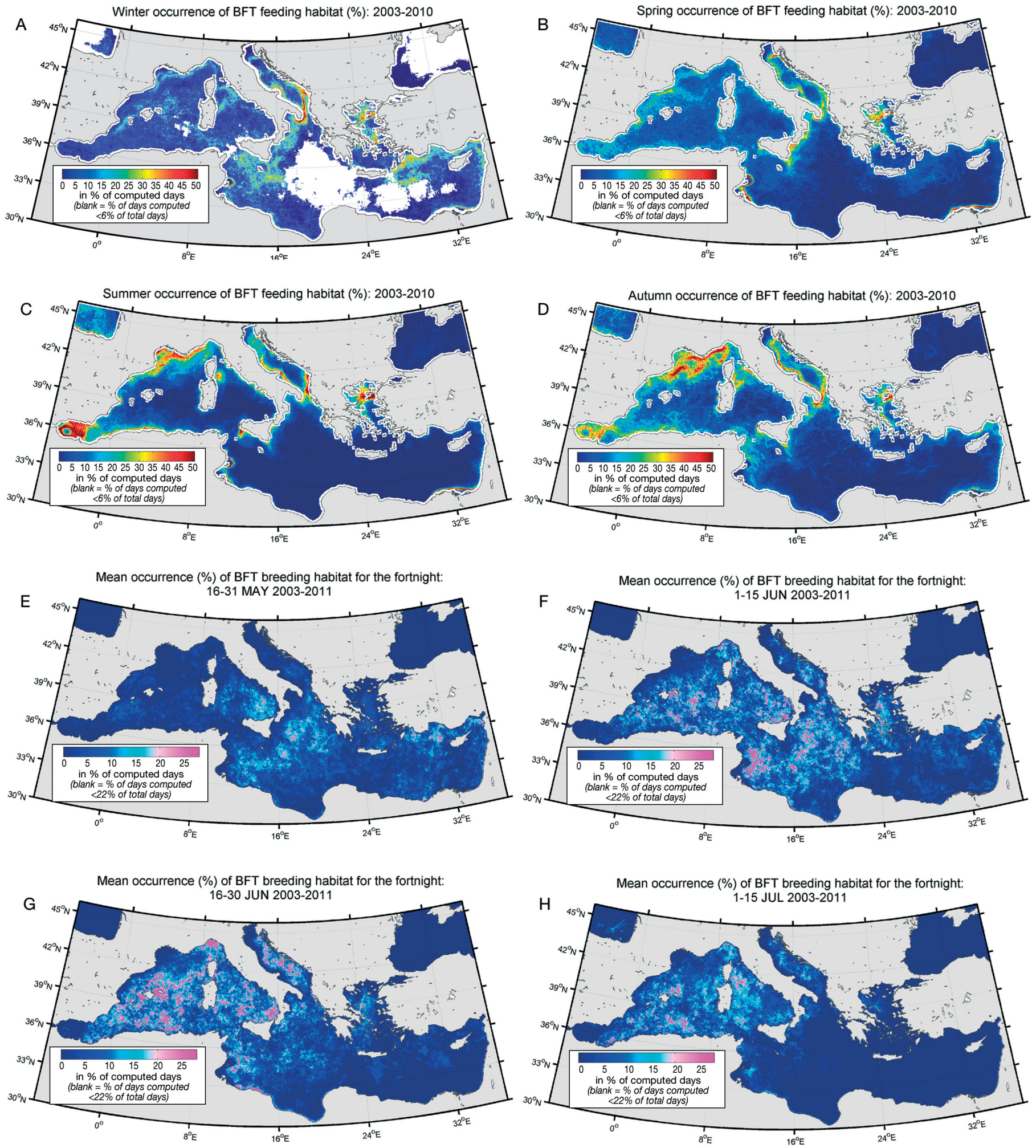

Fig. 7. Thunnus thynnus. (A-D) Seasonal composite of Atlantic bluefin tuna feeding habitat in the Mediterranean Sea for the period 2003-2010, as percentage of total days where satellite data was available: (A) winter, (B) spring, (C) summer, (D) autumn. A minimum value of $6 \%$ of available data was applied to show consistent maps. (E-H) Mean fortnight composite (2003-2010) of bluefin tuna spawning habitat in the Mediterranean Sea as percentage of total days where satellite data was available: (E) second half of May, (F) first and (G) second half of June, and (H) first half of July. A minimum value of $22 \%$ of available data was applied to show consistent maps 
even higher year-to-year variations; the most spectacular occurring around Sardinia in 2006 (Fig. 6E). This anomaly was supported by unusual purse seine fishing west of Sardinia in June 2006 (J. M. Fromentin pers. obs.) as well as the observation of numerous ABFT juveniles of $\sim 35 \mathrm{~cm}$ in September 2006 in the coastal area southeast of Sardinia (P. Addis pers. comm.). In 2003, the spawning habitat displayed smaller favourable areas than on average or in 2006 (Fig. 6B).

\section{Spatial variability at the seasonal scale}

Both the feeding and spawning habitats were also highly variable between seasons, but these variations were not equally distributed. Regarding the feeding habitat, the northwestern Mediterranean Sea and the Alboran Sea were more dynamic than the others, as these key feeding areas were mostly active in summer and autumn, while the other key feeding grounds (Adriatic Sea and Aegean Sea) appear more stable all year round (Fig. 7A-D). The summer and autumn are also characterized by a more concentrated feeding habitat than in winter and spring. The ABFT spawning habitat occurs from mid-May to July following a heating wave and stratification build-up from east to west as shown by the mean fortnight composites (Fig. 7E-H). Although the inter-annual variability is high (Fig. 6), this longitudinal dynamic is recurrent every year.

\section{Main temporal patterns}

To better quantify these different sources of variations at the basin scale, we computed the surface of the Mediterranean Sea displaying favourable feeding or spawning habitats for ABFT for each month of each year for the 2003-2009 period (Fig. 8). Regarding the feeding habitat, the seasonal cycle was well marked with minimum surface values during summer ( $5 \%$ of the Mediterranean Sea) and maximum surface values in late autumn (10\% of the basin). Year-to-year variations may reach 25 to $35 \%$, but were less important than the seasonal variation. However, there was no specific trend in the year-toyear variations. Regarding the spawning habitat, the seasonal pattern is even more obvious, as the spawning is strongly restricted in time (i.e. from May to July). As expected from the literature, the maximum values mostly occurred in June and ranged from $4.7 \%$ to $8.1 \%$ of the Mediterranean Sea (2008 and
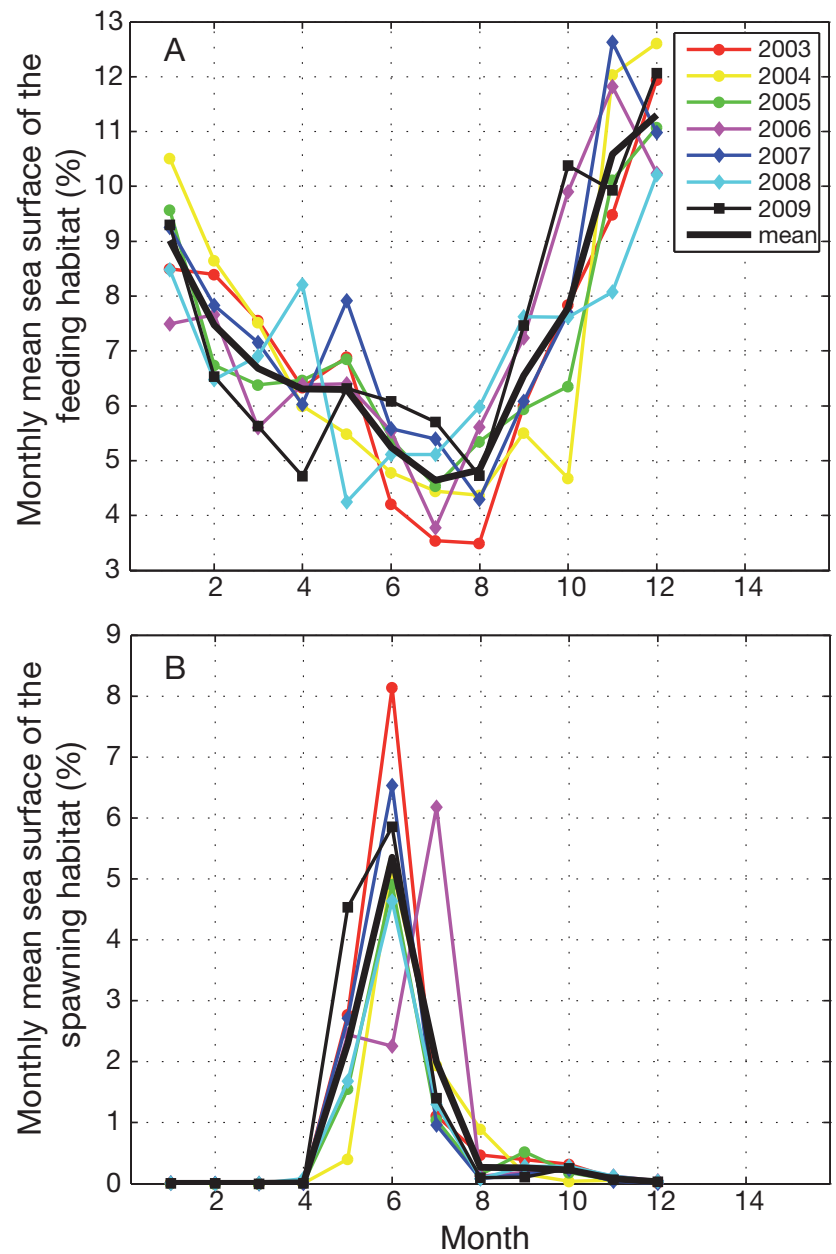

Fig. 8. Monthly mean surface (\%) of the Mediterranean Sea estimated to be favourable for Atlantic bluefin tuna Thunnus thynnus (A) feeding and (B) spawning from 2003 to 2009 and for the 2003-2009 period

2003, respectively). However, the size of spawning habitat did not always peak in June. In 2009, the largest areas favourable for spawning took place almost equally in May and June, while in 2006 it peaked in July (owing to an unusual extension around Sardinia; Fig. 6E). The standard deviation of the predicted surface for the spawning habitat was about 50 to $65 \%$ for the period May to July, twice that of the feeding habitat. This higher variability is expected since the former is mainly influenced by meteorological conditions (stratification build-up) and the latter by a mixed influence of meteorological conditions and the general oceanic circulation.

The mean annual values of habitat surfaces for the period 2003-2009 were 2 to $3 \times$ less variable than the monthly surfaces (results not shown). Similarly, the variability was higher for the spawning habitat (high in 2003, 2006 and 2009 and low in 2005 and 2008) 
than for the feeding habitat (high in 2006, 2007 and 2009 and low in 2003). More interestingly, there was a $6 \%$ increase in the surface of the potential feeding habitat over the period 2003-2009. However, the 7-yr time series of the present study remains too short to reach any clear conclusion about the variations at low frequency.

\section{DISCUSSION}

Our approach provides, for the first time, a synoptic view of the potential feeding and spawning habitats of ABFT in the Mediterranean Sea as well as their spatial and temporal variations, which are both crucial to evaluate the utility of MPAs or to correct key inputs in stock assessment models such as the Catch per Unit Effort indices. Nonetheless, this approach has a few limitations, mostly the cloud cover, and the quantity and distribution (in time and space) of ABFT observations. Druon (2010) discussed the impact of cloud cover on the habitat coverage in the Mediterranean Sea, which is seasonal (maximum in winter and minimum in summer). For instance, for the years 2006 and 2007, the mean annual habitat coverage when computing the daily feeding habitat of $22 \pm 6 \%$ of the Mediterranean Sea is lower than that of the period from May to July with a value of $29 \pm 8 \%$. For comparison with the feeding habitat, the mean habitat coverage when computing the spawning habitat from May to July is significantly higher with a value of $55 \pm 14 \%$. For operational use, the 3-day composite habitat map is therefore fairly well covered during the spawning (and currently fishing) season. We also investigated the use of other sensors for SST and CHL in parallel, i.e. MODIS-Terra for NSST and SeaWiFS for CHL, which lag 3 and $1.5 \mathrm{~h}$ behind MODISAqua, respectively. The mean increase of habitat coverage due to changes in cloud coverage when using both pairs of sensors was $13 \%$ for the spawning habitat and $36 \%$ for the feeding habitat in 2003 (Aulanier \& Druon 2010). When the model was calibrated using only SeaWiFS/MODIS-Terra, there was little difference in habitat classification (5\% for feeding and $11 \%$ for spawning) from that with the calibration based on MODIS-Aqua. This indicates that the data from both sensors could be used in parallel (Aulanier \& Druon 2010). Although this approach needs to be confirmed with additional ABFT observations, the combination of several satellite sensors appears to be a promising approach to partially circumvent the difficulties induced by cloud cover. The use of smoother and cloud free SST data, such as pro- posed by GHRSST (https://www.ghrsst.org/), could improve the signal:noise ratio by removing a proportion of high frequency noise that can be observed in the potential spawning habitat when computing the $30 \mathrm{~d}$ gradient. This needs to be further explored on ABFT, but also on other species for which the SST coverage is poorer, such as tropical tuna species. However, the lack of ABFT observations and the high cloud coverage during winter in the western and central Mediterranean Sea as well as the low number of ABFT observations in the eastern Mediterranean Sea remain the most prominent technical limitations of our current approach.

One might question what potential habitat represents compared to effective habitat. Most of the current habitat models (Barry \& Elith 2006) or catcheffort standardization for fish stock assessments (Maunder \& Punt 2004) rely on statistical approaches (e.g. regression models such as generalized linear or additive models) where correlation or co-occurrence is examined between the targeted species and environmental variables. However, such approaches also display some limitations, e.g. in some cases the absence of the given species remains uncertain (e.g. for marine mammals) and biases can be introduced due to the lack of homogeneous distribution of the population in the area of interest. Moreover, the absolute values of environmental variables at the position of the occurrence of the species might be not relevant, because large pelagic species, such as ABFT, albacore tuna, right or rorqual whales, seem to seek specific oceanic features showing high horizontal gradients such as fronts (see e.g. Royer et al. 2004, Schick et al. 2004, Stokesbury et al. 2004, Zainuddin et al. 2006, Doniol-Valcroze et al. 2007, Rooker et al. 2008, Pershing et al. 2009, Lawson et al. 2010). This is in line with Barry \& Elith (2006) when reviewing errors and uncertainties of species distribution models, who concluded that the most robust modelling approaches are likely to be those in which care is taken to match the model with knowledge of ecology. Therefore, we believe that the potential habitat, as defined in this study, better describes the functional habitat than standard GLM or GAM approaches, especially for highly migratory species which spend a significant time searching for favourable areas for their reproduction. Because the potential habitat is defined by oceanic features, it was necessary to define its size using the factor $W_{f}$ in the cost function $f_{\min }$ (see 'Methods: Calibration of the habitat model') and we found an optimal extension. This parameter is likely to include several characteristics, such as the distance covered by the target species per time unit, 
the quantity and quality of environmental information collected and the fish or school behaviour. Therefore, this parameter is likely to be speciesspecific. Since the potential habitat is traced by meso-scale oceanic structures close to (but not directly by) ABFT presence, a single observation may change habitat classification depending on the respective size of each habitat (driven by the respective parameterization). In fact, while processing different calibration runs, a few observations $(<5 \%)$ changed habitat classification in areas where feeding and spawning habitats are close to each other (in the Balearic Islands area).

Emphasis was placed on the use of relative satellite data (computation of spatial and temporal gradients) with a minor contribution of absolute values which are less consistent. As mentioned above, satellitederived SST and CHL data are influenced by specific measurement characteristics (water depth and atmospheric influence, respectively) leading to higher uncertainties in the absolute values compared to field measurements. However, the variability at meso-scale and over several weeks indicates that satellite data adequately describe the oceanic features. The spatial resolution of $4.6 \mathrm{~km}$ appears to be relevant to detect oceanic features of importance for ABFT. The use of the original (non geo-projected) data at $1 \mathrm{~km}$ resolution is likely to allow a slight improvement in the model performances and would allow accessing the potential feeding habitat closer to the coast $(\sim 3 \mathrm{~km}$ vs. $\sim 15 \mathrm{~km}$ currently). However, this would also notably impede progress in the methodology by increasing the computing time for a minor benefit.

The present model performs well in areas where both satellite data and ABFT observations are available. Indeed, (1) a large fraction of ABFT observations are in the vicinity of the potential habitat (overall, $80 \%$ of observations are within $9.0 \mathrm{~km}$ of a potential habitat, $n=430$ ), (2) the general shapes of the histograms of ABFT occurrences against distances from the habitat boundary are very satisfactory, (3) the validation with an independent dataset clearly supports the former calibration of the model, (4) further tests showed that potential habitat fitted from ABFT geo-located observations is notably different from the one that could be obtained with random data and (5) the information on fish weight that is not used in the habitat model is in agreement with the model results, as adult ABFT (i.e. fish weight $>30 \mathrm{~kg}$ ) were mostly found within the potential spawning habitat during the spawning season, while juveniles (i.e. fish weight $<30 \mathrm{~kg}$ ) were mostly found close to the potential feeding habitat. Therefore, it could be of interest to obtain access to a larger dataset on ABFT to test whether the characteristics and spatial distribution of the feeding habitat would change when a larger proportion of adult fish is considered. It is also worth noting that the general locations of potential feeding and spawning habitats that have been detected in the Mediterranean Sea by our model are in good agreement with current knowledge (Mather et al. 1995, Fromentin \& Powers 2005, Rooker et al. 2007). Furthermore, the general timing of the spawning as well as the east-west sequence of favourable spawning habitat in the Mediterranean Sea from mid-May to mid-July is also correctly estimated by the model. This result is in agreement with (1) studies on ABFT gonadosomatic index where maximum values were found in late May and early June in the Levantine Sea (eastern Mediterranean Sea), and 2 and 4 wk later in the central (Malta) and western (Balearic Islands) locations, respectively (Heinisch et al. 2008) and (2) the general movement of the purse seine fleet tracking ABFT spawners that start fishing in the Eastern Mediterranean in May and end in July in the Balearic Islands area. The outputs that are not fully supported by current knowledge mostly concern the spawning habitat, especially the areas of the Ligurian Sea, east of Sicily and the northern Aegean Sea. Regarding the Ionian Sea area east of Sicily, the model identified an important potential spawning habitat which is in accordance with the reported occurrence of ABFT larvae in that area (Rooker et al. 2007). Catches of large individuals (spawners) in the Gulf of Syrta since 2002 were reported in May and June which suggest that this area could be a key spawning ground, although few ABFT larvae have been reported. The importance of the potential feeding and spawning habitat in the Aegean Sea also appears to be disproportionate, considering current knowledge and the low occurrence of commercial fleets in this area. However, the potential spawning habitat in this area is mainly inferred over the 2003-2009 period by the event of 2008 (Fig. 6G). The purse seine fleet was also twice as efficient in fishing in spawning grounds as in feeding grounds (Druon 2010) and a significant number of pop-up positions from electronic tags are reported in the Aegean Sea compared to the rest of the Mediterranean Sea (De Metrio et al. 2005, review in Rooker et al. 2007). However, no satisfactory explanation has been found for the remaining problematic area, the northern Ligurian Sea. This problem might reveal some limitations in the current model, especially the lack of one or more covariates to specify the spawn- 
ing habitat, such as currents. Another improvement of the method for the potential feeding habitat would be to estimate the age of frontal structures in order to retain only features old enough $(\sim 2 \mathrm{wk})$ to sustain the development of micro-zooplankton, which in turn attracts higher-level predators. Additional information of ABFT spatial distribution needs to be collected, especially from current electronic tagging experiments in the Mediterranean Sea (Fromentin 2010), to help us to distinguish between possible spurious predictions of habitat and incomplete knowledge. Nevertheless, the general consistency of the model outputs with current knowledge clearly indicates that defining a potential habitat on a given set of oceanographic structures appears to be relevant for ABFT.

The application of this methodology on ABFT reveals other patterns of interest. The feeding habitat displays a stretched shape while the spawning habitat is patchier. Depending on the occurrence and size of each pattern type, it could be worth investigating whether the geometrical aspect has an impact on the capacity of the species to find its favourable habitat. If most of the feeding and spawning grounds are in agreement with current knowledge, the present study further shows large spatial and temporal variations in both habitats at both the seasonal and annual scales (thanks to the high temporal and spatial resolution of remote-sensing data). This result, which is in agreement with local observations from scientists or fishermen, is of particular interest as it embraces, for the first time, a synoptic view of the entire Mediterranean Sea over 7 continuous years. Thus, this approach can detect special features, such as the low occurrence of potential feeding habitat in the Mediterranean Sea in 2003 or the unusually strong occurrence of potential spawning habitat around Sardinia in 2006 (the latter being supported by fisheries information and the high abundance of small ABFT southeast of Sardinia 2 mo later).

Such unusual events shed light on key biological and ecological processes. The 2006 Sardinian episode as well as the general spatial variability in the potential spawning habitat would indeed advocate spatial learning, rather than imprinting, when explaining the underlying mechanisms of ABFT homing (Fromentin \& Powers 2005). It would be worth sampling (including with electronic tags) that area to investigate whether ABFT born in 2006 return during June-July in subsequent years. Overall, the high seasonal and annual variability in potential habitats that we detected is in agreement with the outputs from electronic tagging, which empha- sizes high variations in migratory behaviour among individuals in terms of both season and year (e.g. Block et al. 2005, Sibert et al. 2006b, Galuardi et al. 2010). Similarly, the analyses of long-term fisheries data have already put forward the key role of changes in ABFT migration patterns to explain the long-term fluctuations in trap catches (Ravier \& Fromentin 2001, 2004) as well as the appearance and disappearance of key ABFT fishing grounds during the 20th century (Tiews 1978, Mather et al. 1995, Fromentin 2009). Thus our study shows that changes in ABFT migration patterns could be related to natural variations in their feeding and spawning habitats, but analysis of the key role of prey distribution variability was beyond the scope of this study.

Finally, mapping potential fish habitats may have a possible role in the spatial management and the control of fisheries, as this has been already shown for the Chilean anchovy, southern bluefin tuna and swordfish (see Yáñez et al. 2004, Hobday \& Hartmann 2006, Hobday et al. 2010). The near real-time maps have also been recently proposed for ABFT to define open and closed fishing areas or to enforce controls at sea (Casey et al. 2009, Druon 2010). The composites over a decade may also be useful to define essential habitats requiring protection, preferably through a web of MPAs. This generic approach can be transposed a priori to other pelagic species (e.g. other pelagic tuna, small pelagic, and shallow demersal fish). The approach has also been successfully applied on the finback whale Balaenoptera physalus (potential feeding habitat only) in the Mediterranean Sea with similar performances (Druon et al. unpubl.). This top predator, which mainly feeds on krill in this area, displays a feeding habitat that is well defined by frontal structures. This gives further support to the key role of the frontal systems in the productivity of the Mediterranean Sea. Chl a fronts are indeed sufficiently persistent to sustain a complete food web starting with micro-zooplankton. Planktonic feeders, such as anchovy and sardine, are therefore likely to also be related to these productive frontal systems while being a prey for ABFT (Royer et al. 2004, Schick et al. 2004). We now plan to apply our approach of using earth observation data to describe potential habitat for anchovy, hake and tropical pelagic tunas (skipjack and yellowfin tunas).

Acknowledgements. The authors thank the Ocean Biology Processing Group (Code 614.2) at the GSFC, Greenbelt, MD 20771 , for the efficient production and distribution of ocean colour and sea surface temperature data. The authors are especially grateful to R. Delponte who provided a significant fraction of ABFT sightings from his logbooks as well as Ifre- 
mer for the field campaigns targeting ABFT. We are thankful for valuable comments and suggestions provided by 4 anonymous reviewers and the subject editor. We also express our gratitude to E. MacAoidh for correcting the English.

\section{LITERATURE CITED}

Aulanier F, Druon JN (2010) Habitat modelling of marine species derived from satellite data: technical aspects. European Commission EUR 24498 EN-Scientific and Technical Research series - Joint Research Centre. Publications Office of the European Union, Luxembourg

Bard FX, Bach P, Josse E (1998) Habitat et écophysiologie des thons: Quoi de neuf depuis 15 ans? Collect Vol Sci Pap ICCAT 50:319-342

Barry S, Elith J (2006) Error and uncertainty in habitat models. J Appl Ecol 43:413-423

Beddington JR, Agnew DJ, Clark CW (2007) Current problems in the management of marine fisheries. Science 316:1713-1716

Block BA, Teo SLH, Walli A, Boustany A and others (2005) Electronic tagging and population structure of Atlantic bluefin tuna. Nature 434:1121-1127

Bonhommeau S, Farrugio H, Poisson F, Fromentin JM (2010) Aerial surveys of bluefin tuna in the western Mediterranean Sea: retrospective, prospective, perspectives. Collect Vol Sci Pap ICCAT 65:801-811

Brill R, Lutcavage M, Metzer G, Bushnell P and others (2002) Horizontal and vertical movements of juvenile bluefin tuna (Thunnus thynnus, in relation to oceanographic conditions of the western North Atlantic, determined with ultrasonic telemetry. Fish Bull 100:155-167

Casey J, Vanhee W, Druon JN (eds) (2009) Advice on stocks of interest to the European Community in areas under the jurisdiction of CCAMLR, CECAF, WECAF, ICCAT, IOTC, IAATC, GFCM, NAFO, and stocks in the North East Atlantic. Report of the European Scientific, Technical and Economic Committee for Fisheries, Vigo, Spain, 19-23 October 2009. EC Joint Research Centre, Brussels. http://stecf.jrc.ec.europa.eu/c/document_library/get_file ?p_l_id=53322\&folderId=44863\&name=DLFE-4716.pdf

Connor DW, Gilliland PM, Golding N, Robinson P, Tod D, Verling E (2006) UKSeaMap: the mapping of seabed and water column features of UK seas. Joint Nature Conservation Committee, Peterborough. www.vliz.be/imisdocs/ publications/125357.pdf

de Juan S, Lleonart J (2010) A conceptual framework for the protection of vulnerable habitats impacted by fishing activities in the Mediterranean high seas. Ocean Coast Manage 53:717-723

De Metrio G, Arnold GP, de la Serna JM, Block BA and others (2005) Movements of bluefin tuna (Thunnus thynnus L.) tagged in the Mediterranean Sea with pop-up satellite tags. Collect Vol Sci Pap ICCAT 58:1337-1340

> Doniol-Valcroze T, Berteaux D, Larouche P, Sears R (2007) Influence of thermal fronts on habitat selection by four rorqual whale species in the Gulf of St. Lawrence. Mar Ecol Prog Ser 335:207-216

> Druon JN (2010) Habitat mapping of the Atlantic bluefin tuna derived from satellite data: Its potential as a tool for the sustainable management of pelagic fisheries. Mar Policy 34:293-297

Fromentin JM (2009) Lessons from the past: investigating historical data from bluefin tuna fisheries. Fish Fish 10: 197-216

Fromentin JM (2010) Tagging bluefin tuna in the Mediterranean Sea: challenge or mission impossible? Collect Vol Sci Pap ICCAT 65:812-821

Fromentin JM, Powers JE (2005) Atlantic bluefin tuna: population dynamics, ecology, fisheries and management. Fish Fish 6:281-306

Fromentin JM, Restrepo V (2001) Recruitment variability and environment: Issues related to stock assessments of Atlantic tunas. Collect Vol Sci Pap ICCAT 52:1780-1792

Fromentin JM, Farrugio H, Deflorio M, De Metrio G (2003) Preliminary results of aerial surveys of bluefin tuna in the western Mediterranean Sea. Collect Vol Sci Pap ICCAT 55:1019-1027

Galuardi B, Royer F, Golet W, Logan J, Neilson J, Lutcavage M (2010) Complex migration routes of Atlantic bluefin tuna (Thunnus thynnus) question current population structure paradigm. Can J Fish Aquat Sci 67:966-976

García A, Alemany F, Velez-Belchí P, Jurado JLL and others (2005) Characterization of the bluefin tuna spawning habitat off the Balearic Archipelago in relation to key hydrographic features and associated environmental conditions. Collect Vol Sci Pap ICCAT 58:535-549

Garcia A, Alemany F, Velez-Belchi P, Lopez Jurado JL and others (2006) Characterization of the bluefin tuna spawning habitat off the Balearic archipelago in relation to key hydrographic features and associated environmental conditions. ICCAT, SCRS/2003/76

Halpern BS, Warner RR (2002) Marine reserves have long and lasting effects. Ecol Lett 5:361-366

> Heinisch G, Corriero A, Medina A, Abascal FJ and others (2008) Spatio-temporal pattern of bluefin tuna (Thunnus thynnus L. 1758) gonad maturation across the Mediterranean Sea. Mar Biol 154:623-630

Hilborn R, Orensanz J, Parma A (2005) Institutions, incentives and the future of fisheries. Philos Trans R Soc B 360: $47-57$

Hobday AJ, Hartmann K (2006) Near real-time spatial management based on habitat predictions for a longline bycatch species. Fish Manag Ecol 13:365-380

Hobday AJ, Hartog JR, Timmiss T, Fielding J (2010) Dynamic spatial zoning to manage southern bluefin tuna (Thunnus maccoyii) capture in a multi species longline fishery. Fish Oceanogr 19:243-253

> Humston R, Ault JS, Lutcavage M, Olson DB (2000) Schooling and migration of large pelagic fishes relative to environmental cues. Fish Oceanogr 9:136-146

ICCAT (2007) Report of the 2006 Atlantic Bluefin Tuna Stock Assessment Session. Collect Vol Sci Pap ICCAT 60: $652-880$

ICCAT (2009) Report of the 2008 Atlantic Bluefin Tuna Stock Assessment Session. Collect Vol Sci Pap ICCAT 64: 1-352

Inagake D, Yamada H, Segawa K, Okazaki M, Nitta A, Itoh T (2001) Migration of young bluefin tuna, Thunnus orientalis Temminck et Schlegel, through archival tagging experiments and its relation with oceanographic conditions in the Western North Pacific. Bull Natl Res Inst Far Seas Fish 38:53-81

Kitagawa T, Kimura S, Nakata H, Yamada H (2004) Diving behavior of immature, feeding Pacific bluefin tuna (Thunnus thynnus orientalis) in relation to season and area: the East China Sea and the Kuroshio-Oyashio transition region. Fish Oceanogr 13:161-180 
Larkin PA (1996) Concepts and issues in marine ecosystem management. Rev Fish Biol Fish 6:139-164

> Laurs RM, Fiedler PC, Montgomery DR (1984) Albacore tuna catch distributions relative to environmental features observed from satellites. Deep-Sea Res A 31: 1085-1099

> Lawson GL, Castleton MR, Block BA (2010) Movements and diving behavior of Atlantic bluefin tuna Thunnus thynnus in relation to water column structure in the northwestern Atlantic. Mar Ecol Prog Ser 400:245-265

Le Fèvre J (1986) Aspects of the biology of frontal systems. Adv Mar Biol 23:163-299

Lehodey P, Bertignac M, Hampton J, Lewis A, Picaut J (1997) El Nino Southern Oscillation and tuna in the western Pacific. Nature 389:715-718

Lioka C, Kani K, Nhhala H (2000) Present status and prospects of technical development of tuna sea-farming. Cah Opt Méditerr 47:275-285 http://ressources.ciheam. org/om/pdf/c47/00600628.pdf

Mather FJ, Mason JM Jr, Jones A (1995) Historical document: life history and fisheries of Atlantic bluefin tuna. NOAA Tech Memo NMFS-SEFSC-370, Miami, FL

Matlab (2006) Matlab R2006a, The language of technical computing, MathWorks, Natick, MA

> Maunder MN, Punt AE (2004) Standardizing catch and effort data: a review of recent approaches. Fish Res 70:141-159

> Munk P, Larsson PO, Danielsen D, Moksness E (1995) Larval and small juvenile cod Gadus morhua concentrated in the highly productive areas of a shelf break front. Mar Ecol Prog Ser 125:21-30

Nelder JA, Mead R (1965) A simplex method for function minimization. Comput J 7:308-313

Nishikawa Y, Honma M, Ueyanagi S, Kikawa S (1985) Average distribution of larvae of oceanic species of scombroid species, 1956-1981. Far Seas Fisheries Research Laboratory Series S 12

Olson DB, Hitchcock GL, Mariano AJ, Ashjian CJ, Peng G, Nero RW, Podesta GP (1994) Life on the edge: marine life and fronts. Oceanography 7:52-60

Pershing AJ, Record NR, Monger BC, Mayo CA and others (2009) Model-based estimates of right whale habitat use in the Gulf of Maine. Mar Ecol Prog Ser 378:245-257

> Polovina JJ, Howell E, Kobayashi DR, Seki MP (2001) The transition zone chlorophyll front, a dynamic global feature defining migration and forage habitat for marine resources. Prog Oceanogr 49:469-483

Ravier C, Fromentin JM (2001) Long-term fluctuations in the Eastern Atlantic and Mediterranean bluefin tuna population. ICES J Mar Sci 58:1299-1317

Ravier C, Fromentin JM (2004) Are the long-term fluctuations in Atlantic bluefin tuna (Thunnus thynnus) population related to environmental changes? Fish Oceanogr 13:145-160

Rooker JR, Alvarado Bremer JR, Block BA, Dewar H and others (2007) Life history and stock structure of Atlantic bluefin tuna (Thunnus thynnus). Rev Fish Sci 15:265-310

Rooker JR, Secor DH, DeMetrio G, Kaufman AJ, Belmonte Rios A, Ticina V (2008) Evidence of trans-Atlantic movement and natal homing of bluefin tuna from stable isotopes in otoliths. Mar Ecol Prog Ser 368:231-239

> Royer F, Fromentin JM, Gaspar P (2004) Association

Editorial responsibility: Konstantinos Stergiou,

Thessaloniki, Greece between bluefin tuna schools and oceanic features in the western Mediterranean. Mar Ecol Prog Ser 269:249-263

Sammari C, Millot C, Prieur L (1995) Aspects of the seasonal and mesoscale variabilities of the Northern Current in the western Mediterranean Sea inferred from the PROLIG-2 and PROS-6 experiments. Deep-Sea Res I 42: 893-917

Schaefer KM (2001) Reproductive biology of tunas. In: Block BA, Stevens ED (eds) Tuna physiology, ecology and evolution. Academic Press, San Diego, CA, p 225-270

Schick RS, Lutcavage ME (2009) Inclusion of prey data improves prediction of bluefin tuna (Thunnus thynnus) distribution. Fish Oceanogr 18:77-81

Schick RS, Goldstein J, Lutcavage ME (2004) Bluefin tuna (Thunnus thynnus) distribution in relation to sea surface temperature fronts in the Gulf of Maine (1994-96). Fish Oceanogr 13:225-238

> Sibert JR, Lutcavage ME, Nielsen A, Brill RW, Wilson SG (2006a) Interannual variation in large-scale movement of Atlantic bluefin tuna (Thunnus thynnus) determined from pop-up satellite archival tags. Can J Fish Aquat Sci 63:2154-2166

Sibert J, Hampton J, Kleiber P, Maunder M (2006b) Biomass, size, and trophic status of top predators in the Pacific Ocean. Science 314:1773-1776

Stokesbury MJW, Teo SLH, Seitz A, O'Dor RK, Block BA (2004) Movement of Atlantic bluefin tuna (Thunnus thynnus) as determined by satellite tagging experiments initiated off New England. Can J Fish Aquat Sci 61: 1976-1987

Sumaila UR, Zeller D, Watson R, Alder J, Pauly D (2007) Potential costs and benefits of marine reserves in the high seas. Mar Ecol Prog Ser 345:305-310

Teo SLH, Boustany A, Dewar H, Stokesbury MJW and others (2007) Annual migrations, diving behavior, and thermal biology of Atlantic bluefin tuna, Thunnus thynnus, on their Gulf of Mexico breeding grounds. Mar Biol 151:1-18

Tiews K (1978) On the disappearance of bluefin tuna in the North Sea and its ecological implications for herring and mackerel. Rapp P-V Reùn Cons Int Explor Mer 172: 301-309

Ullman DS, Cornillon PC (2000) Evaluation of front detection methods for satellite-derived SST data using in situ observations. J Atmos Ocean Technol 17:1667-1675

Uotani I, Saito T, Hiranuma K, Nishikawa Y (1990) Feeding habit of bluefin tuna Thunnus thynnus larvae in the western north Pacific Ocean. Bull Jpn Soc Sci Fish 56: 713-717

- Walli A, Teo SLH, Boustany A, Farwell CJ and others (2009) Seasonal movements, aggregations and diving behavior of Atlantic bluefin tuna (Thunnus thynnus) revealed with archival tags. PLoS ONE 4:e6151

Yáñez E, Silva C, Nieto K, Barbieri MA, Martínez G (2004) Using satellite technology improve Chilean purseine fishing fleet. Gayana 68:578-585

Zainuddin M, Kiyofuji H, Saitoh K, Saitoh SI (2006) Using multi-sensor satellite remote sensing and catch data to detect ocean hot spots for albacore (Thunnus alalunga) in the northwestern North Pacific. Deep-Sea Res II 53: 419-431

Submitted: November 26, 2010; Accepted: July 26, 2011

Proofs received from author(s): September 30, 2011 